\title{
Potent CYP3A4 Inhibitors Derived from Dillapiol and Sesamol
}

\author{
Ana Francis Carballo-Arce, ${ }^{\dagger, \ddagger}$ Vikrant Raina, ${ }^{*},+\odot$ Suqi Liu, ${ }^{\S}$ Rui Liu, ${ }^{\S}$ Victoria Jackiewicz, ${ }^{\ddagger}$ \\ David Carranza, ${ }^{\dagger,}$ John Thor Arnason, ${ }^{\S}$ and Tony Durst*, \\ †Escuela de Química, Universidad Nacional, Heredia 86-3000, Costa Rica \\ ${ }^{\ddagger}$ Department of Chemistry and Biomolecular Sciences, and ${ }^{\S}$ Department of Biology, University of Ottawa, Ottawa K1N 6N5, \\ Canada
}

\section{Supporting Information}

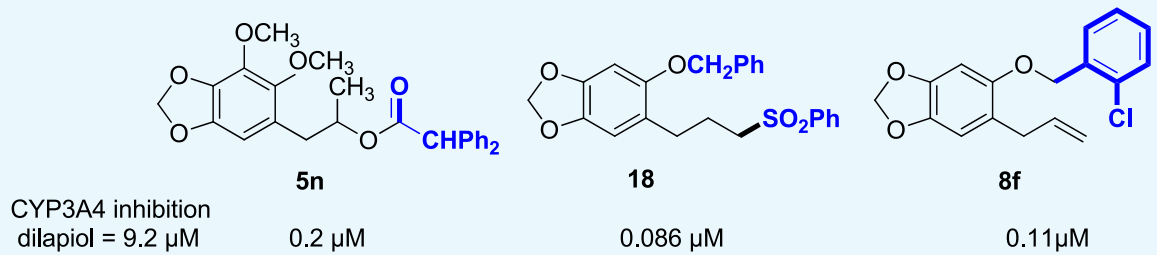

ABSTRACT: Synthesis of 50 analogues of the natural insecticide synergists, dillapiol and sesamol, is reported. These were evaluated as potential insecticide synergists based on their inhibition of human CYP3A4. The most potent inhibitors have a relatively large hydrophobic substituent at either position 5 or 6 of these molecules. For example, 5-(benzyloxy)-6-(3phenylsulfonyl)propyl)benzo[ $d][1,3]$ dioxole $(\mathbf{1 8})$ and the diphenyl acetate of $(6,7$-dimethoxybenzo[ $d][1,3]$ dioxol-5-yl)propan1 -ol (5n) show inhibitory concentrations for $50 \%$ activity $\mathrm{IC}_{50}$ values of 0.086 and $0.2 \mu \mathrm{M}$, respectively. These compounds are 106 and 46 times more potent than dillapiol whose $\mathrm{IC}_{50}$ for the inhibition of CYP3A4 is $9.2 \mu \mathrm{M}$. The ortho-chloro analogue (8f), whose activity is 86 times the activity of dillapiol, is the most potent of the fourteen 5-(benzyloxy-6-(2 propenyl)benzo[d][1,3]dioxoles prepared for this study.

\section{INTRODUCTION}

In our study of Mesoamerican and African traditional medicines, ${ }^{1,2}$ we have observed the use of plants including the genus Piper as nontargeted adjuvant agents combined with other targeted plant therapies. Extracts of these plants were found to be a potent inhibitor of enzymes of metabolism including CYP3A4, 3A5, and 3A7, which suggests that they could inhibit the metabolism at phase I of conventional drugs in vivo as well as act as pharmacoenhancers in herbal mixtures. An active inhibitory principle of the neotropical Piper aduncum was identified as the neolignan dillapiol. Dillapiol is a potent inhibitor of cytochrome CYP3A4. ${ }^{3}$ Pharmacoenhancement by dillapiol was demonstrated in mice acutely infected with Piper berghei, where we found that dillapiol has no antimalarial activity but greatly enhanced the plasma levels and efficacy of the antimalarial compound gedunin. ${ }^{4}$ The synergistic potential of dillapiol combined with pyrethroids against mosquitoes had also been described. ${ }^{5}$

Dillapiol has also been long known as an insecticide synergist. A recent study reported that dillapiol effectively synergized the efficacy of pyrethrin in resistant strains of Colorado potato beetle. ${ }^{6}$ A pilot study of a small set of dillapiol analogues with the botanical larvicide, $\alpha$-terthienyl, showed that modification of the molecule could lead to more effective synergists, but the quantitative structure-activity relationship (QSAR) models were not very robust because of uncertainties in the $\mathrm{LC}_{50}$ (lethal concentration) values.
Piperonyl butoxide (PBO) has been used as an insecticide synergist for more than 60 years and is today by far the most commonly used insecticide synergist. Typical databases indicate that it is a component in more than 1500 products where the active ingredient is either a synthetic or naturally occurring insecticide. ${ }^{8}$ The ratio of $\mathrm{PBO}$ to active ingredient is variable depending on the application. It can range from $3: 1$ to 20:1 with the typical ratio being 5:1. Although PBO is generally viewed as nontoxic to humans and assigned to category IV by the US EPA, recent reports focusing on neurological developments indicate that potential problems have generated some concerns. ${ }^{8-10}$

The European Union has recognized the need for improved insecticide synergists and announced in 2013 an award of 1 million Euros to a consortium of companies and research organizations to "develop insecticide synergists for agricultural, household, and public health use based on the knowledge of the interaction of $\mathrm{PBO}$ with metabolic enzymes in the insect pests". 11

To gain further insight into dillapiol and its analogues as insecticide synergists, an expanded series of dillapiol analogues have been prepared for the present study by exploring a range of modifications of the parent molecule. Sesamol was also used as a starting material for the preparation of related derivatives

Received: $\quad$ March 31, 2019

Accepted: May 20, 2019

Published: June 24, 2019 
Table 1. Inhibition of CYP3A4 by Esters Derived from Dillapiol via Alcohols 2 and 3

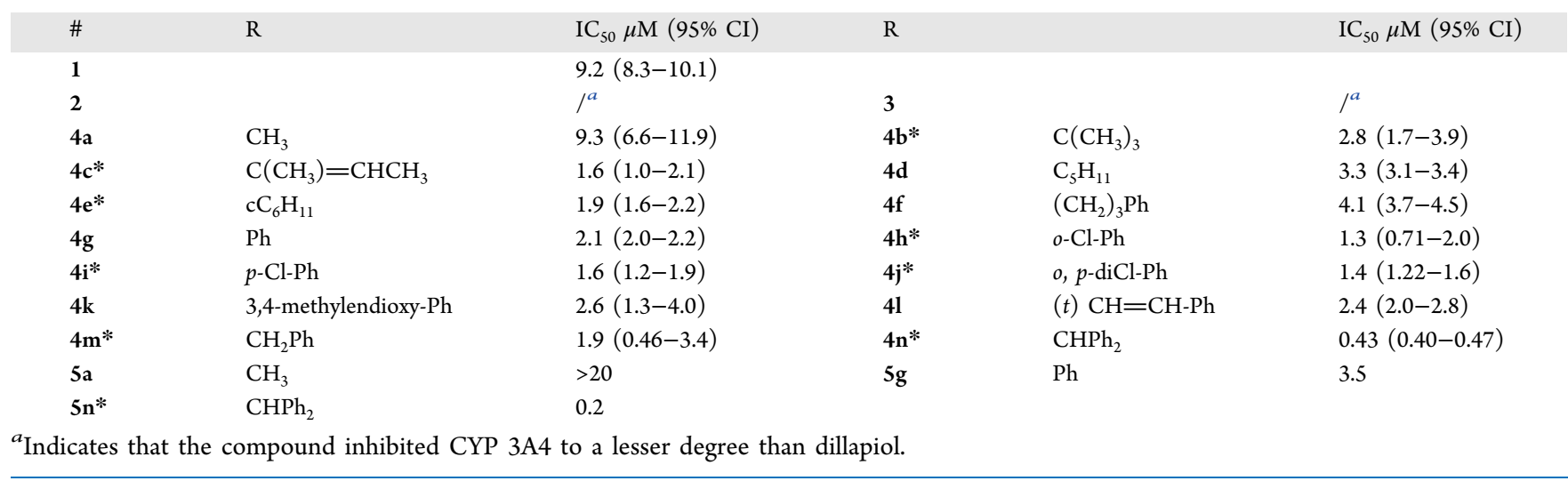

Table 2. Inhibition of CYP3A4 by Esters Derived from Sesamol via Alcohols 9 and $10^{a}$

\begin{tabular}{|c|c|c|c|c|c|c|c|}
\hline$\#$ & $\mathrm{R}_{1}$ & $\mathrm{R}_{2}$ & $\mathrm{IC}_{50}(9 \mu \mathrm{M})(95 \% \mathrm{CI})$ & $\#$ & $\mathrm{R}_{1}$ & $\mathrm{R}_{2}$ & $\mathrm{IC}_{50}(\mu \mathrm{M})(95 \% \mathrm{CI})$ \\
\hline $11 a$ & $\mathrm{CH}_{3}$ & $\mathrm{Ph}$ & $2.1(1.5-2.7)$ & $11 \mathrm{~b}$ & $\mathrm{CH}_{2}-\mathrm{Ph}$ & $\mathrm{Ph}$ & $5.8(5.4-6.2)$ \\
\hline $11 c^{*}$ & $\mathrm{CH}_{2} \mathrm{Ar}$ & $\mathrm{Ph}$ & $0.36(0.26-0.46)$ & $11 d$ & $\mathrm{CH}_{3}$ & ${ }^{t} \mathrm{CH}=\mathrm{CHPh}$ & $17.2(13.6-20.8)$ \\
\hline $11 \mathrm{e}$ & $\mathrm{CH}_{2} \mathrm{Ph}$ & ${ }^{t} \mathrm{CH}=\mathrm{CHPh}$ & $4.7(4.0-5.5)$ & $11 f^{*}$ & $\mathrm{CH}_{3}$ & $\mathrm{CHPh}_{2}$ & $0.47(0.25-0.69)$ \\
\hline $11 \mathrm{~g}^{*}$ & $\mathrm{CH}_{2} \mathrm{Ph}$ & $\mathrm{CHPh}_{2}$ & $1.0(0.97-1.08)$ & $11 \mathrm{~h}$ & $\mathrm{CH}_{2} \mathrm{Ph}$ & $\mathrm{CH}_{2} \mathrm{Ar}$ & $1.4(1.2-1.5)$ \\
\hline $11 i^{*}$ & $\mathrm{CH}_{2} \mathrm{Ar}$ & $\mathrm{CHPh}_{2}$ & $0.22(0.09-0.35)$ & $12 *$ & $\mathrm{CH}_{2} \mathrm{Ph}$ & $\mathrm{CHPh}_{2}$ & 0.16 \\
\hline
\end{tabular}

missing one of the two methoxy groups present in dillapiol and its analogues. All analogues were evaluated in a CYP3A4 inhibition assay using a highly uniform and purified cloned commercial enzyme preparation. The inhibitory concentrations for $50 \%$ activity ( $\mathrm{IC}_{50}$ values) obtained from this method had tight confidence intervals (CIs). As the human CYP3A4 enzyme has considerable similarity with the insect versions, ${ }^{12}$ the results from these studies should be translatable to the application of these compounds as potential insecticide synergists. Indeed, we have shown this to be the case. ${ }^{13} \mathrm{~A}$ number of ethers derived from sesamol which are significantly more potent CYP3A4 inhibitors than dillapiol have been evaluated as potential insecticide synergists of different insecticides by BASF scientists in various locations throughout the world. The results were sufficiently promising and have prompted a European patent application. ${ }^{14}$

\section{MATERIALS AND METHODS}

CYP3A4 Inhibition Assay. Enzyme inhibition assays were conducted with cytochrome P450-BD Gentest CYP3A4 (City, State) with the CytoFluor 4000 fluorescence measurement system (Applied Biosystems, Foster City, CA) as described by Budzinski et al. $^{7}$ Briefly, assays were performed in clearbottom, opaque-welled, 96-well microtiter plates (Corning Costar, Corning, NY) using dibenzyl fluorescein (DBF, SigmaAldrich, Milwaukee, WI) as a substrate. Wells were designated as either "control", "control blank", "test", or "test blank". Control wells consist of $\mathrm{ddH}_{2} \mathrm{O}$ and $\beta$-nicotinamide adenine dinucleotide phosphate (NADPH) solution; control blank wells consist of $\mathrm{H}_{2} \mathrm{O}$ and buffer solution; test wells consist of the dillapiol analogues at a particular concentration and NADPH solution; and test blank wells consist of the corresponding analogue compounds and buffer solution. Enzyme solution was added to all wells. Fluorescence was measured at $485 \mathrm{~nm}$ excitation with a $20 \mathrm{~nm}$ bandwidth filter. All measurements were carried out in triplicate.
Statistical Analysis. Percent inhibition values were calculated based on differences in fluorescence between the control/control blank wells and test/test blank wells by the formula

$$
\begin{aligned}
& {[1-(\text { Test } t=X-t=0)-(\text { test blank } t=X-t=0) /} \\
& \text { (control } t=X-t=0)-(\text { control blank } t=X-t \\
& =0)] \times 100
\end{aligned}
$$

where $t=X$ and $t=0$ are the reading values of the control/ control blank/test/test blank wells at the end and beginning of running $X$ min, respectively.

The median inhibition percent $\left(\mathrm{IC}_{50}\right)$ of each analogue was determined with logarithmic curves plotted by different concentration and percent inhibition. The dillapiol relative inhibition activity was obtained by the formula

$$
\mathrm{IC}_{50} \text { of dillapiol/ } \mathrm{IC}_{50} \text { of tested compound }
$$

As the aim of the research was to find the analogues possessing significantly higher CYP3A4 inhibition activity than dillapiol (positive control), the analogues which showed more than two times the $\mathrm{IC}_{50}$ value higher than dillapiol were labeled as "/" and no data are shown for such compounds in Tables 1 and 2. Statistical analysis of $\mathrm{CIs}$ and range of $\mathrm{IC}_{50}$ values observed were carried out using GraphPad Prism 5; these are shown in the table of the Supporting Information.

Synthesis of Dillapiol and Sesamol Analogues. Dillapiol was obtained via steam distillation of the fruit of $P$. aduncum collected in the Sarapiqui region of Costa Rica. A typical distillation of $3 \mathrm{~kg}$ of fruit when steam distilled with $3 \mathrm{~L}$ of water yielded between 30 and $35 \mathrm{~g}$ ( 1 to $1.2 \%$ ) of essential oil whose proton NMR indicated dillapiol with more than $95 \%$ purity. This material was considered sufficiently pure for transformation to the various intermediates and final products. Dillapiol can also be isolated by steam distillation of the leaves and branches of P. aduncum; the typical yields were in the 0.3 and $0.15 \%$ range for leaves and branches, respectively. The 
latter materials tended to have greater amounts of impurities relative to dillapiol compared to that obtained from the fruit. It is well recorded in the literature ${ }^{15}$ that the composition of the essential oil obtained from $P$. aduncum varies greatly for different geographical locations. The dillapiol content of our Costa Rican sample was as high as that obtained from one of the samples [sample G, collected at Road Manaus-Caracarao, $\mathrm{km} 30$ (AM), 97.3\%]. Our yield of oil was only $1-1.2 \%$ versus $3.0 \%$ reported by Maia et al. ${ }^{15}$ Sesamol was purchased from Sigma-Aldrich and used as such. Standard, well-known chemical transformations were employed to produce various analogues.

A group of 17 esters was prepared via Scheme 1 . Hydroboration of dillapiol, 1, with borane-dimethyl sulfide in

Scheme 1. Preparation of Esters Starting with Dillapiol
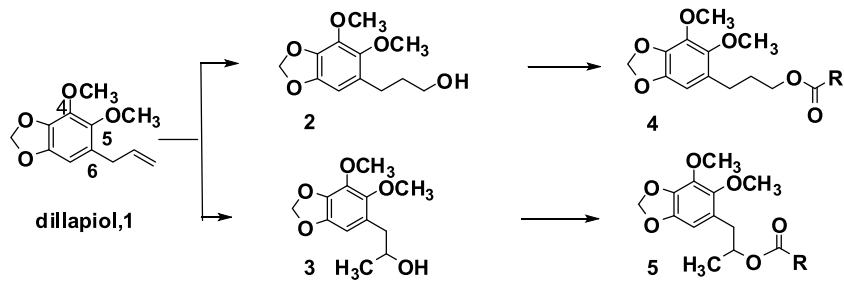

tetrahydrofuran gave, after reductive workup, mainly the expected primary alcohol 2 along with minor amounts of the secondary alcohol 3 . These isomers were separated via flash silica gel chromatography. Both isomers were esterified with different-sized aliphatic and aromatic acids either by reaction with the respective acid chloride or by coupling the acid and alcohol with the help of the coupling reagent DCC. An additional 10 esters and 14 ethers were prepared starting with sesamol in order to investigate the importance of the 4methoxy group in dillapiol. Sesamol, 6, was $O$-allylated by the reaction with allyl bromide in the presence of potassium carbonate. The resultant allyl ether underwent a clean Claisen rearrangement upon heating to $190{ }^{\circ} \mathrm{C}$ in decalin to give the ortho-allylated phenol 7. Subsequent $\mathrm{O}$-alkylation provided ethers 8. Hydroboration of $\mathbf{8 b}\left(\mathrm{R}=\mathrm{CH}_{3}\right)$ and $\mathbf{8 d}(\mathrm{R}=$ $\mathrm{CH}_{2} \mathrm{Ph}$ ) yielded the primary and secondary alcohols $\mathbf{9}$ and $\mathbf{1 0}$, respectively. Acylation of these gave compounds with the general formula 11 and 12, Scheme 2. All compounds were characterized by both ${ }^{1} \mathrm{H}$ and ${ }^{13} \mathrm{C}$ NMR and high-resolution mass spectrometry, which assured their structure assignments (see the Supporting Information).

The above compounds were tested in the CYP3A4 assay. The results are presented as inhibition activity relative to dillapiol activity $=1$. The primary data set including mean $\mathrm{IC}_{50}$ values and $95 \%$ CIs for esters, 17 prepared from dillapiol and 10 from sesamol, are provided in Tables 1 and 2, respectively. Although the raw $\mathrm{IC}_{50}$ values of 27 ester analogues showed a lower trend (i.e., higher inhibition) than that of dillapiol (9.2 $\mu \mathrm{M})$, statistical analysis revealed that only 15 analogues possessed significantly greater CYP3A4 inhibition activity than dillapiol $(\mathrm{d} f=47,96 ; F=106.5 ; P<0.05)$. These are highlighted with $*$ in these tables. For the remaining compounds, Tables $3-5$, only their inhibition activity relative to dillapiol is presented. To ensure consistency, dillapiol was included as the standard in each set of measurements, typically 5 to 8 compounds. The $\mathrm{IC}_{50}$ value for dillapiol was consistent in the 8.9-9.2 $\mu \mathrm{M}$ range.

\section{RESULTS AND DISCUSSION}

Much of the impetus of this research came from an earlier observation by our group that the tertiary alcohol 13 obtained by condensation of the allyl anion derived by the reaction of dillapiol with $n$-BuLi in THF at $-78{ }^{\circ} \mathrm{C}$ with benzophenone strongly inhibited CYP3A4. ${ }^{16}$ The synthesis of 13 was repeated, and its CYP3A4 inhibition was found to be 5.8 times more potent than that of dillapiol. The hydrogenolysis product 14 and the alkene metathesis product 15 had similar potency, while the dillapiol dimer 16 was 13 times more potent than dillapiol ${ }^{17}$ (Table 3).

Both the alcohols 2 and 3 were less potent than dillapiol in inhibiting CYP3A4. The data in Table 1 show that for the esters derived from the primary alcohol 2 , an increase in size of the $\mathrm{R}$ group, particularly if near the ester function itself, resulted in increased CYP3A4 inhibition. For example, the acetate $4 a\left(\mathrm{R}=\mathrm{CH}_{3}\right)$ has essentially the same inhibitory effect as dillapiol. The change in $\mathrm{R}$ from $\mathrm{CH}_{3}(\mathbf{4 a})$ to $n \mathrm{C}_{5} \mathrm{H}_{11}$ (4d) to cyclohexyl $(4 \mathbf{e})$ to $\mathrm{Bu}^{t}(4 \mathrm{a})$ resulted in increased inhibition by factors of $2.8,3,4$, and 4.8 , respectively. The benzoyl ester (4h) is 4.4 times more potent inhibitor than the methyl ester. Chlorine substituents on the aromatic ring further increase the potency of these compounds to statistically significant values of greater than $6(4 \mathbf{h}, 4 \mathbf{i}, 4 \mathbf{j})$. The greatest change was observed when a hydrogen in the benzyl group $(4 \mathrm{~m})$ was replaced by a second aromatic ring to yield $\mathrm{R}=$ benzhydryl $(\mathbf{4 n}, \mathbf{5 n})$. This increased inhibition by a factor of 5 makes 4 n 23 times more potent than dillapiol. The benzhydryl ester, 5n, of the secondary alcohol $\mathbf{5}$ is twice as active as $\mathbf{4 n}$ (46 times dillapiol). On the basis of this result, several other benzhydryl esters were prepared. The esters of the secondary alcohol were more potent than those of the isomeric primary alcohol. The benzhydryl ester 12, derived from the secondary alcohol 10 (R $=\mathrm{CH}_{2} \mathrm{Ph}$ ) (Scheme 2), gave an $\mathrm{IC}_{50}$ value of $0.16 \mu \mathrm{M}$ making it almost 60 times more potent than dillapiol. It is among the most potent CYP $3 \mathrm{~A} 4$ inhibitors reported in this study (Scheme 3).

Comparison of the same esters derived from dillapiol and sesamol suggests that the removal of the 4-methoxy group in dillapiol does not have a significant effect on the inhibition of the CYP3A4 enzyme. For example, the benzoyl esters $\mathbf{4 g}$ and

\section{Scheme 2. Preparation of Sesamol Derivatives}

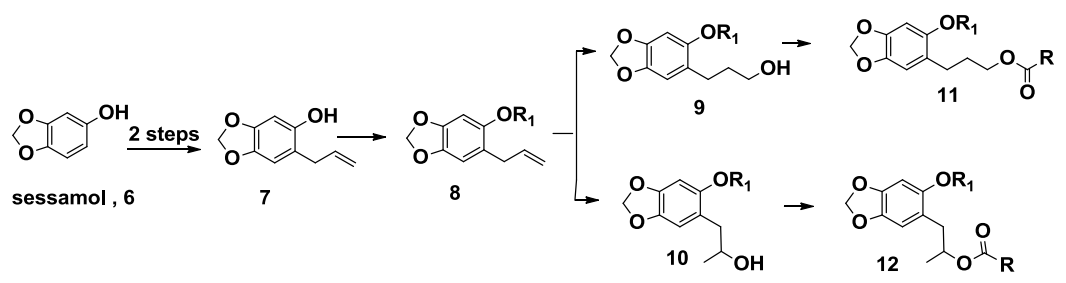


Table 3. Inhibition of CYP3A4 of Compounds Derived from Dillapiol

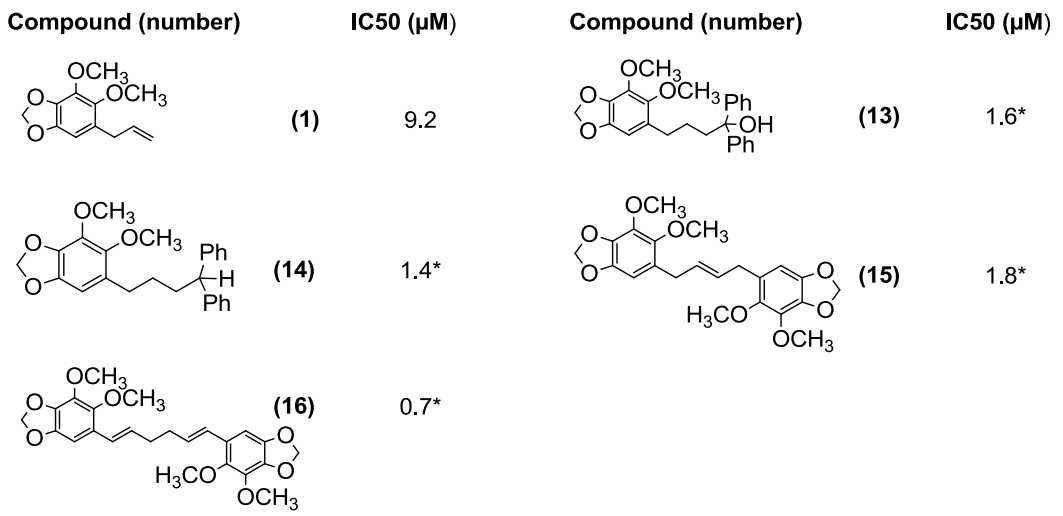

Table 4. Inhibition of CYP3A4 by Ethers Derived from Dillapiol via Compound 2

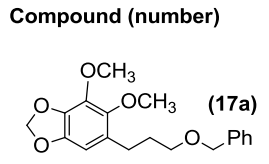

$\begin{aligned} & \text { CYP3A4 inhibition } \\ & \text { relative dillapiol = } 1\end{aligned}$
1.4

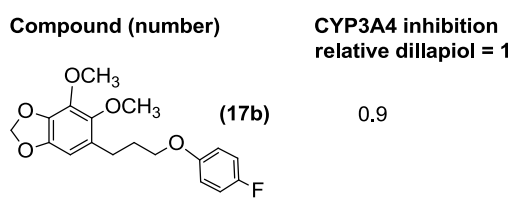

Table 5. Inhibition of CYP3A4 by Ethers Derived from Sesamol

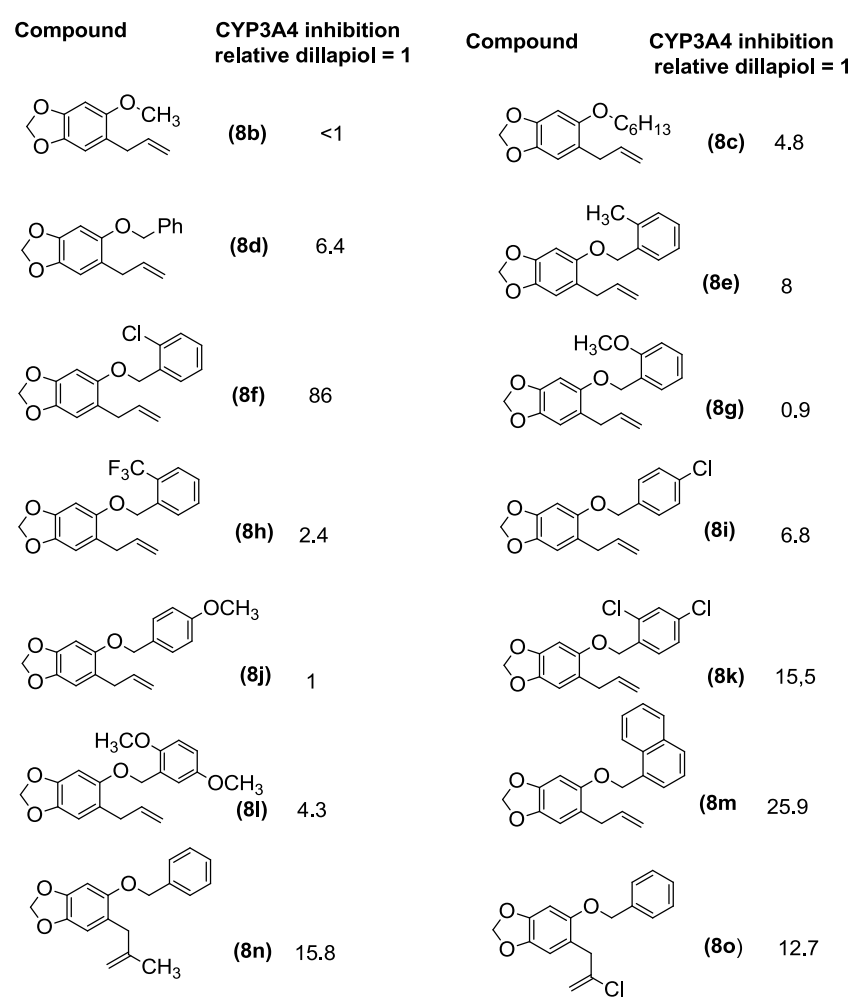

9a inhibit this enzyme to essentially the same extent. The same conclusion can be drawn when one compares data for the benzhydryl esters $4 \mathbf{n}$ and $9 \mathbf{9}$; each of these compounds is approximately 20 times as effective as dillapiol. The replacement of the 5-methoxy group in the sesamol derivatives by benzyloxy groups (Scheme 4) (9b and $\mathbf{9 g}$ ) lowers the

Scheme 4. Esters from Dillapiol and Sesamol ${ }^{a}$
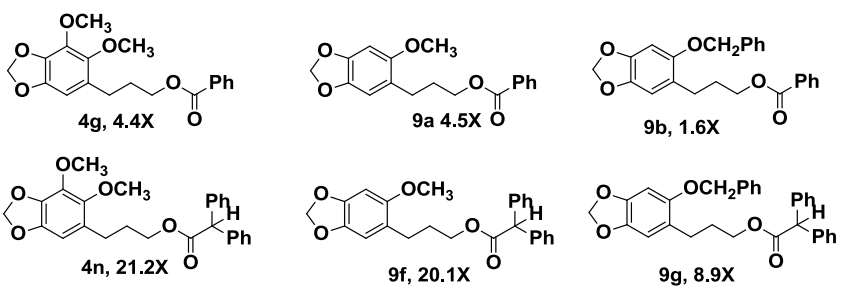

${ }^{a}$ CYP3A4 inhibition, dillapiol $=1$.

inhibitory activity of these compounds by a factor of $2-3$. This is opposite to the results observed for the corresponding 6-allyl derivatives where the benzyl ether $8 \mathbf{c}$ was significantly more active than the methyl ether $\mathbf{8 b}$.

The in vivo bioassays reported by $\mathrm{Liu}^{13}$ showed that only the highly hindered benzhydryl esters had good synergistic activity as anticipated by their in vitro CYP3A4 inhibition. The less hindered esters such as the methyl ester $4 \mathbf{a}$ and the benzoyl ester $\mathbf{4 g}$ showed no insecticide synergism of pyrethrum against the Colorado potato beetle likely due to insect esterase activity, which would convert these compounds back to the inactive alcohols $2,3,9$, and 10 . The metabolically

Scheme 3. Benzhydryl Esters Synthesized and Tested for CYP3A4 Inhibition, Dillapiol = 1

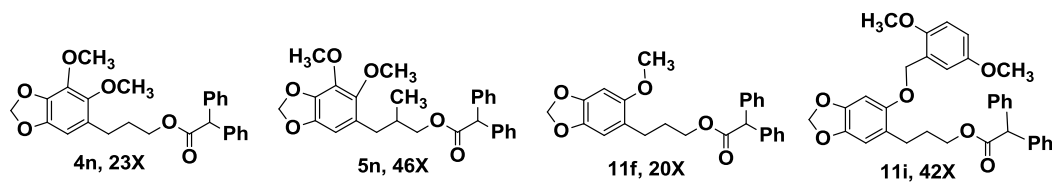


more stable ethers, for example, $\mathbf{8 b}$ showed the increased in vivo synergism relative to dillapiol expected on the basis of its increased inhibition of CYP3A4.

A series of benzylic ethers $\mathbf{8 b} \mathbf{- 8 0}$ were prepared from sesamol via the allylated phenol 7 (Table 5). A number of these compounds where $\mathrm{R}$ is $\mathrm{C}_{6} \mathrm{H}_{13}$ and $\mathrm{CH}_{2} \mathrm{Ph}$ showed modest enhancements in potency in comparison to dillapiol with the hexyl ether showing 4.8-fold and the benzyl ether 6.8fold increases, respectively. Most of the other analogues had similar CYP3A4 inhibitory activity with values ranging from 0.9 times the activity of dillapiol for the $O$-methoxy derivative $\mathbf{8 g}$ to 8 times for the $O$-methyl compound $\mathbf{8 e}$. Several derivatives stood out, in particular, the $O$-chloro analogue 8 f and the 1-naphthyl ether 8m, which inhibited CYP3A4 86 and 26 times more effectively than dillapiol. These compounds have inhibitory activity comparable to the most potent benzhydryl esters $5 \mathrm{n}$ and $\mathbf{1 1 i}$ and the sulfones 18 and 19 . The benzyl ethers $8 \mathbf{n}$ and $8 \mathbf{8}$, which have 2-methylpropenyl and 2-chloropropenyl side chain at $\mathrm{C} 6$, respectively, were 15 and 12.6 times more potent inhibitors than dillapiol, suggesting that a combination of a more hindered side chain at C6 coupled with appropriate ortho-substitution in the 5-benzyloxy moiety could lead to even more potent CYP3A4 inhibitors. Replacement of the benzoyl ester function in $\mathbf{4} \mathbf{g}$ by a benzyl ether yielding $17 \mathbf{a}$ and $17 \mathbf{b}$ resulted in a decrease of the in vitro potency (Table 4).

A group of benzylic ethers 8 were selected by BASF for evaluation as insecticide synergists against economically important insects in combination with common insecticides and their potential to be registered by Environmental Protection agencies. The initial results are encouraging and will be reported when the evaluation is complete. ${ }^{18}$

\section{CONCLUSIONS}

Qualitative analysis of the inhibition data for a variety of esters indicates that the larger acyl group attached to alcohols 4, 5, 11, and 12 gives higher in vitro inhibition of CYP3A4. Additionally, it appears that the same esters derived from the secondary alcohols, for example, $5 n$ and $\mathbf{1 2}$, are approximately twice as potent as those obtained from the isomeric primary alcohols, for example, $4 \mathrm{n}$ and $\mathbf{1 1 i}$. In the case of ethers $\mathbf{8 b}-\mathbf{8 o}$, the replacement of the remaining 5-methoxy group by other larger substituents such as $O$-hexyl, $O$-benzyl, in particular, several ortho-substituted benzyl analogues, and $O$-1-naphthyl resulted in significant increases in the inhibitory property of these compounds relative to dillapiol.

The replacement of the diphenylacetic acid moiety in compounds such as $10 \mathrm{i}$ and $\mathbf{1 2}$ by a phenylsulfonyl group resulted in the most potent CYP3A4 inhibitors we have produced thus far with 18 and 19 (Scheme 5) having $\mathrm{IC}_{50}$ values of 0.086 and $0.13 \mu \mathrm{M}$, respectively. Thus, 18 is 107

Scheme 5. Preparation of Sulfones 18 and 19
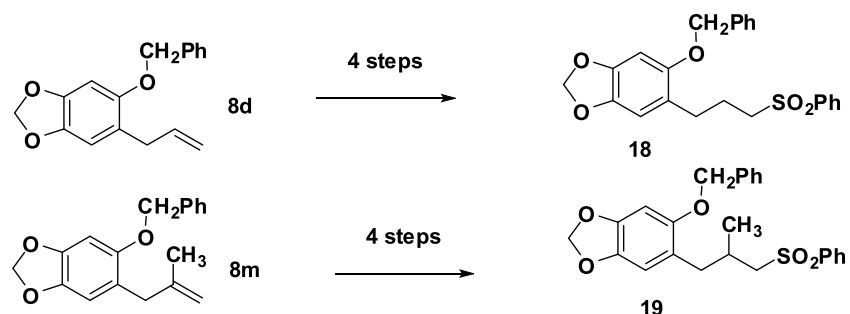

times and 19 is 70 times more potent than dillapiol as inhibitors of this CYP 3A4 enzyme. The sulfones, unlike the esters, are not subject to esterase metabolism in the insects and therefore more likely to be effective in field trials.

Additional structure modifications, potentially guided by a QSAR developed from the available data, ${ }^{16,17,19}$ designed to enhance the potency of sesamol and dillapiol derivatives as CYP3A4 inhibitors, in particular, various ether and sulfone analogues, and the testing of these compounds in in vitro and the field will be reported in the future.

\section{ASSOCIATED CONTENT}

\section{S Supporting Information}

The Supporting Information is available free of charge on the ACS Publications website at DOI: 10.1021/acsomega.9b00897.

${ }^{1} \mathrm{H}$ NMR and ${ }^{13} \mathrm{C}$ NMR spectra and experimental procedure of each compound synthesized (PDF)

\section{AUTHOR INFORMATION}

\section{Corresponding Authors}

*E-mail: Vrain032@uottawa.ca. Phone: 613-618-7943 (V.R.).

*E-mail: tdurst@uottawa.ca (T.Z.).

ORCID

Vikrant Raina: 0000-0001-5941-7028

\section{Funding}

The authors would like to thank BASF Canada and the Natural Sciences and Engineering Research Council of Canada CRD program (CRDPJ417954-1) for support of this work.

Notes

The authors declare no competing financial interest.

\section{ACKNOWLEDGMENTS}

We thank Dr. Cameron Oehlschlager, ChemTica SA, Santo Domingo, Costa Rica, for providing the facilities for the largescale isolation of dillapiol via steam distillation.

\section{REFERENCES}

(1) Agbonon, A.; Eklu-Gadegbeku, K.; Aklikokou, K.; Gbeassor, M.; Akpagana, K.; Tam, T. W.; Arnason, J. T.; Foster, B. C. In vitro inhibitory effect of West African medicinal and food plants on human cytochrome P450 3A subfamily. J. Ethnopharmacol. 2010, 128, 390394.

(2) Amiguet, V. T.; Arnason, J. T.; Maquin, P.; Cal, V.; Vindas, P. S.; Poveda, L. A consensus ethnobotany of the Q"eqchi” Maya of Southern Belize. Econ. Bot. 2005, 59, 29-42.

(3) Belzile, A.-S.; Majerus, S. L.; Podeszfinski, C.; Guillet, G.; Durst, T.; Arnason, J. T. Dillapiol derivatives as synergists: Structure-activity relationship analysis. Pestic. Biochem. Physiol. 2000, 66, 33-40.

(4) Omar, S.; Godard, K.; Ingham, A.; Hussain, H.; Wongpanich, V.; Pezzuto, J.; Durst, T.; Eklu, C.; Gbeassor, M.; Sanchez-Vindas, P.; Poveda, L. Antimalarial activities of gedunin and 7-methoxygedunin and synergistic activity with dillapiol. Ann. Appl. Biol. 2003, 143, 135141.

(5) Gomes, E. O.; Nunomura, S. M.; Marrinotti, O.; Tadei, P. Synergistic potential of dillapiole combined with pyrethroids against mosquitoes. Vector Bio. J. 2016, 1. DOI: 10.4172/2473-4810.1000114

(6) Liu, S. Q.; Scott, I. M.; Pelletier, Y.; Kramp, K.; Durst, T.; Sims, S. R.; Arnason, J. T. Dillapiol: A Pyrethrum Synergist for Control of the Colorado Potato Beetle. J. Econ. Entomol. 2014, 107, 797-805.

(7) Budzinski, J. W.; Foster, B. C.; Trudeau, V. L.; Drouin, C. E.; Bafi-Yeboa, N.; Arnason, J. T. The interaction of selected phytochemicals, HIV drugs, and commercial-source herbal teas and 
capsules with human cytochrome P450 $3 \mathrm{~A} 4$ and P-glycoprotein.

Pharm. Biol. 2008, 46, 53-65.

(8) Dais, B. Office of Pesticide Programs. Piperonyl Butoxide: Human Risk Scoping Document in Support of Registration Review United States Environmental Protection Agency, Washington D.C., 2010, Reregistration Case 2525.

(9) Wang, J.; Lu, J.; Mook, R. A., Jr.; Zhang, M.; Zhao, S.; Barak, L. S.; Freedman, J. H.; Lyerly, H. K.; Chen, W. The Insecticide Synergist Piperonyl Butoxide Inhibits Hedgehog Signaling: Assessing Chemical Risks. Toxicol. Sci. 2012, 128, 517-523.

(10) Lanphear, B. P.; Hornung, R.; Khoury, J.; Yolton, K.; Baghurst, P.; Bellinger, D. C.; Canfield, R. L.; Dietrich, K. N.; Bornschein, R.; Greene, T.; Rothenberg, S. J.; Needleman, H. L.; Schnaas, L.; Wasserman, G.; Graziano, J.; Roberts, R. Low-Level Environmental Lead Exposure and Children's Intellectual Function: An International Pooled Analysis. Environ. Health Perspect. 2005, 113, 894-899.

(11) Beer, A. EU Funds Insecticide Synergist Research; AGROW, 2013; Vol. 676, p 13.

(12) Feyereisen, R. Insect CYP genes and 450 enzymes. Insect Molecular Biology and Biochemistry; Gilbert, L. I., Ed.; Elsevir Academic Press, 2012; pp 236-316.

(13) Liu, S. Ph.D. Thesis, University of Ottawa, 2015.

(14) European Patent application 181616459, (March 14, 2018).

(15) Maia, J. G. S.; Zohhbi, M. G. B.; Andrade, E. H. A.; Santos, A. S.; da Silva, M. H. L.; Luz, A. I. R.; Bastos, C. N. Constituents of the essential oil of Piper aduncum L. growing wild in the Amazon region. Flavour Fragrance J. 1988, 13, 269-272.

(16) Majerus, S. M.Sc. Thesis, University of Ottawa, 1998.

(17) Carballo-Arce, A. F. Ph.D. Thesis, University of Ottawa, 2014.

(18) Arevalo, A. (BASF). Private communication, 2018.

(19) Raina, V. M.Sc. Thesis, University of Ottawa, 2018. 